\title{
ESG Integration and the Investment Management Process: Fundamental Investing Reinvented
}

\author{
Emiel van Duuren ${ }^{1} \cdot$ Auke Plantinga $^{1} \cdot$ Bert Scholtens $^{1,2}$
}

Received: 3 September 2014/Accepted: 10 March 2015/Published online: 19 March 2015

(C) The Author(s) 2015. This article is published with open access at Springerlink.com

\begin{abstract}
We investigate how conventional asset managers account for environmental, social, and governance (ESG) factors in their investment process. We do so on the basis of an international survey among fund managers. We find that many conventional managers integrate responsible investing in their investment process. Furthermore, we find that ESG information in particular is being used for red flagging and to manage risk. We find that many conventional fund managers have already adopted features of responsible investing in the investment process. Furthermore, we argue and show that ESG investing is highly similar to fundamental investing. We also reveal that there is a substantial difference in the ways in which U.S. and European asset managers view ESG.
\end{abstract}

Keywords ESG investing · Asset management · Survey · Fundamental investing

\section{Introduction}

We investigate how asset managers integrate environmental, social, and governance (ESG) factors in their investment practice. ESG investing focuses on different nonfinancial dimensions of a stock's performance. It specifically relates to the impact of the company on the

Bert Scholtens

1.j.r.scholtens@rug.nl

1 Faculty of Economics and Business, University of Groningen, PO Box 800, 9700 AV Groningen, The Netherlands

2 School of Management, University of Saint Andrews, Saint Andrews, UK environment, a social dimension, and governance. For each dimension, a lot of information on the firm's practices and policies is being collected and analyzed. The analysis is used by a portfolio manager to construct a diversified portfolio. This usually is structured to meet minimum standards with respect to the three dimensions. The main ESG strategies are negative screening (i.e., excluding particular firms or industries), positive screening (i.e., concentrating on particular industries), best-in-class investing (i.e., selecting the best 33 or $25 \%$ regarding ESG), activism (filing petitions and voting on annual general meetings of shareholders), and engagement (meeting with the board of the corporate and trying to convince them to perform better on ESG).

Accounting for ESG in the investment process has been labeled as (socially) responsible investing (SRI) (see Johnsen 2003; Eccles and Viviers 2011). However, there does not seem to be consensus on what the term SRI exactly means for investors (Berry and Junkus 2013). Many academic studies focus on the impact of SRI on financial performance, rather than the exact meaning of SRI. Capelle-Blancard and Monjon (2012) find that most of the SRI literature concludes that the impact on financial performance is limited and not statistically significant. More recent studies, e.g., Humphrey and Tan (2014), confirm this conclusion with the latest data. Capelle-Blancard and Monjon (2012) suggest that most of the papers on SRI focus on financial performance, while using roughly the same methods yielding similar results. Furthermore, they argue that the academic literature on SRI is mostly data driven; the famous 'looking for the keys under the lamppost' syndrome. It appears that too much attention is paid to financial performance, whereas more research seems required on a conceptual and theoretical ground, in particular the aspirations of SRI investors, the relationship 
between regulation and SRI, as well as the assessment of extra-financial performances.

Our study tries to pick up this criticism and specifically looks into more detail regarding how professionals account for ESG factors in the investment process. We are especially interested in how 'ordinary' professionals cope with ESG issues. Hence, our survey is not targeted at managers of ethical, responsible, or green funds, but at managers of conventional investment funds. We use a survey given to more than one hundred portfolio managers. As such, we complement the study of Berry and Junkus (2013) who focus on retail investors. Three surprising and very interesting findings emerge from our study. The first is that many conventional fund managers have adopted features of responsible investing in their investment process. The second is that in many respects ESG investing seems to resemble fundamental investing. The third is that the domicile of the portfolio manager has a distinct impact on responsible investing: US-based managers tend to be skeptical about its benefits, whereas European managers are outright optimistic.

In the remainder of this paper, we first go into ESG integration in relation to the investment process. Then, we introduce our survey and present and discuss the results. We end with a brief conclusion.

\section{ESG Integration}

Eurosif (2014) defines ESG integration as “.... the explicit inclusion by asset managers of ESG risks and opportunities into traditional financial analysis and investment decisions based on a systematic process and appropriate research sources..." Eurosif divides the activities performed by asset managers into three categories: Category 1 ("nonsystematic ESG Integration"): ESG research and analyses made available to mainstream analysts and fund managers; Category 2: Systematic consideration/inclusion of ESG research/analyses in financial ratings/valuations by analysts and fund managers; Category 3: Mandatory investment constraints based on financial ratings/valuations derived from ESG research/analyses (exclusions, under-weighting, and etc.). Eurosif only considers categories 2 and 3 to be consistent with its definition of ESG integration.

Incorporating ESG factors in investment strategies has become a distinct service for many providers of investment services. ESG investing is an approach that focuses on several non-financial dimensions of a stock's performance, including the impact of the company on the environment, a social dimension, and governance. For each of these dimensions, a lot of information on the firm's practices is being collected and analyzed. The outcomes of this analysis are used by a portfolio manager to construct a diversified portfolio. This usually is structured to meet minimum standards with respect to the three dimensions. ESG investing relies on the belief that both investors and society benefit by including ESG information. This optimistic view is very well expressed in Shiller (2013) who discusses the important role of financial markets in supporting many activities in society. In this view, innovation in finance is necessary to keep up with the changes in and required by society.

ESG is not without controversy though. ESG integration potentially adds an unnecessary burden on the investment process imposing costly constraints. Kempf and Osthof (2008) find indeed that mutual funds engaged in ESG investing charge higher expense ratios. In their study, the average difference was 13 basis points and this difference was statistically significant. Other authors emphasize that ESG information provides a positive benefit by providing superior returns. For instance, Derwall et al. (2005) find that equity portfolios with high scores on eco-efficiency (the economic value added relative to the waste produced) score higher riskadjusted returns than portfolios with low scores on eco-efficiency. Edmans (2011), in a study of the hundred best companies to work for in America, reports that high employee satisfaction is to be associated with positive risk-adjusted returns at a statistically significant level. However, when reviewing the empirical literature on the performance of SRI investing, the prevailing notion is that social responsible investing does not yield significant positive riskadjusted returns (Galema et al. 2008; Renneboog et al., 2008). There is even evidence that investing in 'irresponsible' stocks (like tobacco, alcohol, and gambling) might result in extra-financial returns (Hong and Kacperczyck 2009).

It seems fair to state that ESG investing carries a big promise, even bigger than the promise that was once implied in active investing. Active investing is an investment strategy aimed at beating the market index on a risk-adjusted basis. As a strategy it encompasses fundamental analysis with Graham and Dodd (1934) as advocates, and technical analysis with early roots to Charles Dow. While active investing only implies an expectation of positive risk-adjusted returns, ESG investing also promises a better world. In this study, we are going to focus on how ESG affects investment management. Is it really different from traditional active investing? Of the two basic investment approaches, fundamental analysis is probably the most important. In a survey among financial analysts, Chugh and Meador (1984) find clues about what might be important in fundamental investing. They find that analysts have a strong emphasis on the long-term economic and financial performance of a company while preferring stock specific information over general economic prospects. They also attach a high value to the quality of management and the quality of strategic planning. 
When comparing fundamental with ESG investing, we observe several striking similarities: it seems very plausible to argue that the quality of management is strongly related to corporate governance. Furthermore, addressing the interests of the environmental and social interest groups requires a lot of strategic planning. However, the most convincing argument is that the majority of ESG investors believes in beating passive investing. In the remainder of this paper, we will argue that ESG investing is highly similar to fundamental investing. Although ESG investing puts a strong emphasis on non-financial dimensions of corporate performance, in reality it provides a stock selection screen.

\section{Survey}

We surveyed the opinions of portfolio managers with respect to ESG integration using an online questionnaire. The questionnaire was deployed in 2013 among a group of prospective portfolio managers maintained by the sponsor of this study, TKP Investments. TKP Investments is a leading Dutch fiduciary pension fund manager, responsible for the implementation and management of investment strategies for pension funds. The list of prospective managers is a long-list of managers who are monitored by TKP Investments as potential future portfolio managers for its customers. The questionnaire was sent to 251 fund managers and their team of which 14 are under contract and 237 under research at TKP Investments. Initially 83 funds filled out the questionnaire. After a follow-up email this number increased to 126 , resulting in an response rate of $50 \%$. The questions referred to the status with respect to ESG related issues in 2012 (the full questionnaire is included in Appendix 1).

The content of the questionnaire is based on various sources, including the literature on ESG factors, the UN's PRI questionnaire regarding responsible investments, and experts from TKP Investments and Sustainalytics, a policy research and consultancy firm. We first ask for a description of the portfolio managers' investment process in general.

ESG factors relate to environmental (for example, carbon assessment, water and energy consumption, and waste management), social (for example, employee satisfaction, diversity, and human rights), and corporate governance factors (management, board independence, and compensation). Do ESG factors play a role in your investment process? Choose the answer that best describes your approach.

Hence, this is essentially a self-reported assessment of the level of ESG integration. The possible responses are then sorted into four classes from one to four, where the first class contains respondents with no ESG integration, the second class contains respondents who believe that ESG integration is 'implicitly incorporated in the financial numbers' or have ESG integration 'in the back of their minds.' The third class of respondents explicitly use qualitative or quantitative information, whereas the fourth class of respondents use both quantitative and qualitative information and or have detailed policies and procedures for ESG integration.

Then, we ask whether and how they integrate ESG in their processes. This encourages the respondents to think about the relevance of ESG in the investment process. Fund managers make use of several techniques, for example, discounted cash flow analysis and financial ratios. If a fund manager claims to integrate ESG factors into the investment process, then these factors should be part of these techniques. We identify whether ESG information is used to determine the investment universe, whether it is used in the valuation of companies, whether it is used to manage risks, etc. Also, through a multiple choice question, we ask whether separate investment guidelines exist for environmental, social, and governance factors in order to find out if one of the ESG factors is considered more important compared to the others.

Furthermore, with the idea that what gets measured gets managed, attention is paid to the ESG data, systems, and staff that the fund has at its disposal. The more data available, the more likely it is that the data are used in buy and sell decisions regarding stocks. The same holds for ESG staff. Furthermore, we use questions that ask for specific examples that indicate that environmental, social, and/or governance issues have affected the position in a stock. If ESG factors are really considered important by fund managers, then it is likely that in a given year at least some stocks have been bought or sold due to ESG related reasons. A potential disadvantage of a questionnaire is that respondents might give socially desirable answers. In the introduction of the survey, we emphasize that the purpose of this survey is to assess whether and how ESG factors have a part in the investment process.

Table 1 presents the key properties of the respondents in the survey. On average, the managers self-reported that ESG score is 2.32 on a scale ranging from one to four, where one represents no ESG integration and four represents full ESG integration. The average fund manages $€ 3$ billion in assets and is more than 14 years. Four out of five funds are signatories to the UN's Principles for Responsible Investing. The goal of this project is to understand the implications of sustainability for investors and support signatories to incorporate these issues into their investment decision making and ownership practices. $40 \%$ of the funds is located in the U.K., one third in the U.S., and one quarter in continental Europe. 
Table 1 Sample properties

\begin{tabular}{lcrccc}
\hline Variable & Obs & Mean & SD & Min & Max \\
\hline ESG score & 126 & 2.32 & 0.77 & 1 & 4 \\
Risk-adjusted performance (2011) & 112 & -0.34 & 5.37 & -19.59 & 17.1 \\
Risk-adjusted performance (2009-2011) & 107 & 2.13 & 4.47 & -7.42 & 23.79 \\
Asset under management (€bln) & 113 & 3.06 & 4.94 & 0.01 & 28.9 \\
Fund age (years) & 123 & 14.57 & 7.01 & 2 & 31 \\
UNPRI & 126 & 0.80 & 0.40 & 0 & 1 \\
Domicile of manager & & & & & \\
U.K. (\%) & 127 & 0.40 & 0.49 & 0 & 1 \\
Continental Europe (\%) & 127 & 0.25 & 0.43 & 0 & 1 \\
U.S. (\%) & 127 & 0.32 & 0.47 & 0 & 1 \\
\hline
\end{tabular}

ESG score is measured on a four-point scale, where 1 represents respondents with no ESG integration, and 4 represents the highest level of ESG integration. Risk-adjusted performance is measured as an annualized percentage. Fund age is the number of years since inception. UNPRI is a dummy variable indicating whether the manager adheres to the UNPRI principles

Table 2 What is important in ESG investing?

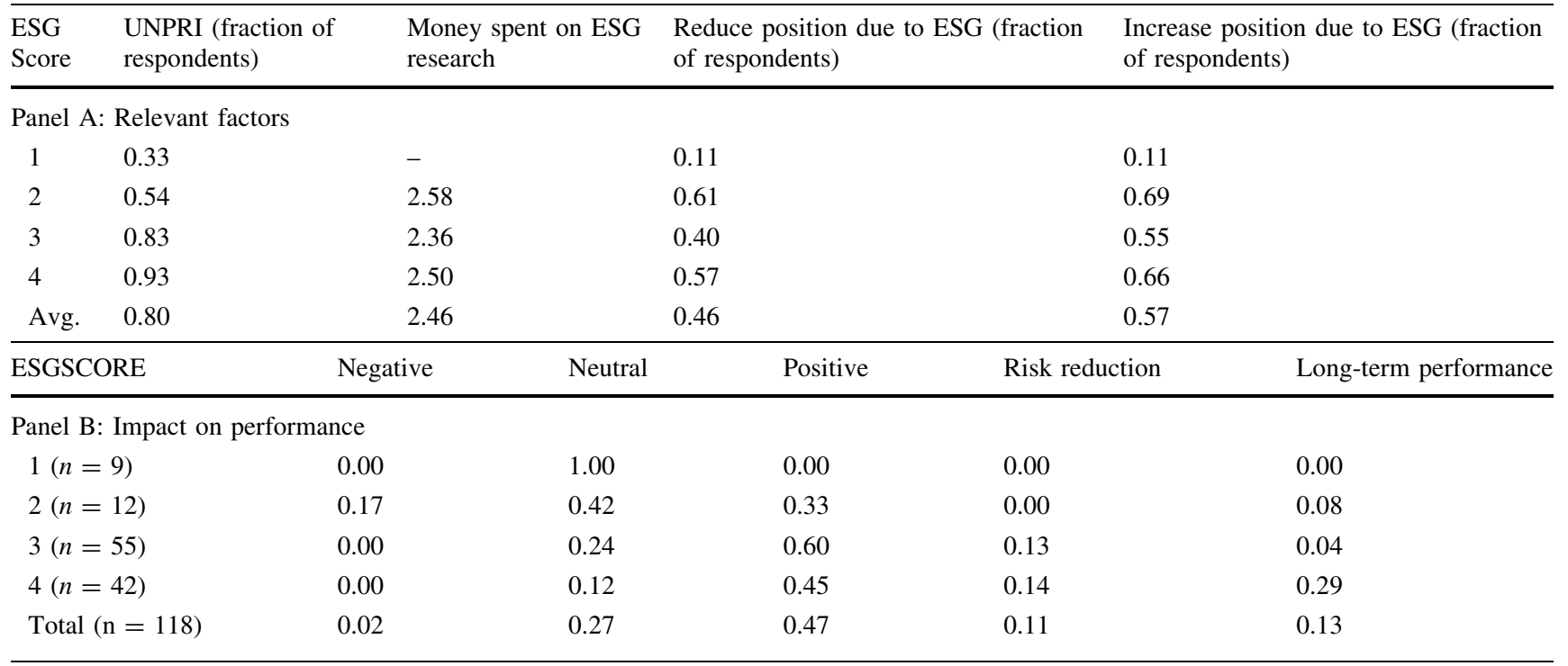

\section{What is Important in ESG Integration?}

Table 2 reports whether the manager is a UN PRI signatory, indicating whether the manager adheres to these principles. As can be observed in this table, the self-reported ESG Score that we use to measure an investor's sophistication with respect to ESG investing is increasing with the participation in these UN principles, which can be seen as a validation of our ESG score.

In order to structure the investment process for ESG investing, it is important to know what is important in this process. Therefore, we asked the respondents to indicate on a five-point scale the relevance of the amount of money spend on ESG specific research, ${ }^{1}$ where 1 indicates no

$\overline{1}$ See Appendix 1 for the exact wording of the questions. relevance and 5 very relevant. Panel A of Table 2 presents the average responses. According to the respondents, the relevance of the amount of money spent on ESG research is on average 2.46 on five-point scale. This is statistically significant at a $1 \%$ level below three, the average of the scale. This is an interesting result given that Kempf and Osthoff (2008) find that ESG mutual funds generally have higher expense ratios. The results from the survey suggest that the respondents do not share the idea that ESG investing should incur substantially higher cost.

Panel A also shows the fraction of respondents answering yes to the following question: During 2012, did you sell or reduce your position in a stock (partly) because of poor environmental, social, or governance concerns? We find that the majority of investors who actively integrate ESG factors in their investment process (ESG levels 2, 3 
and 4) report that they have done so during 2012. We also find that a majority of the same group of investors has bought (additional) shares due to ESG related information. What is perhaps surprising is that during the entire year a large minority of ESG investors did not do any buy or sell as a result of ESG specific information. For these three categories together, $51 \%$ of the managers did not sell a single stock due to a positive ESG signal and $39 \%$ did not buy a single stock due to a negative signal. There are two ways in which one can interpret these results. Either ESG investing is 'game' with a low frequency of news releases or ESG investor are missing many ESG signals. Whatever the explanation, it seems fair to conclude that ESG investing results in little transactions.

Furthermore, we asked the respondents about the perceived impact of ESG integration on the expected riskadjusted outperformance of a mainstream mutual fund. Respondents could indicate a negative impact, a neutral impact, a positive impact, a reduction in risk, or a positive impact on long-term performance. The results regarding these questions are reported in Panel B of Table 2. Most respondents expect a positive impact, either in the short run or in the long run. This expectation becomes stronger with the level of ESG integration of the investor. The higher the level of ESG integration, the more positive the respondent is on the impact of ESG investing on performance, although fewer respondents in the highest class (4) of ESG integration expect a positive impact as compared to the second highest class (3). The respondents in the highest class shifted to an expectation framed in terms of lower risk or a positive impact on the long-term performance.

\section{Implementation of ESG}

It is obvious that proper information is a key ingredient in any investment strategy. The investment management process is largely fueled by the information that investors require in order to assess individual investment opportunities. For this reason, it is important to know what type of information ESG managers really need. We asked the opinion of the respondents with respect to the type of information required. A truly fundamental analyst may want access to the raw data on ESG factors in addition to all the regular financial data. This raw data may include annual company reports on ESG factors, press statements, reports from interest groups, and etc. However, investors may be time-constrained and therefore may have a tendency to use processed data such as ESG ratings. Another issue is to what extent ESG information is driven by market wide movements (i.e., at the sector or country level) or by idiosyncratic components. A lot of ESG information may be market wide, such as changes in regulation on the environment or social conditions. However, news about the individual conditions in a specific firm regarding ESG are likely to be important as well. The respondents were allowed to give multiple responses for the questions reported in Table 3. Since the questions focus on the use of ESG information, there are no answers for respondents that did not engage in ESG investing (i.e., ESGSCORE = 1).

Table 3 shows that respondents on average favor ratings and analysis at a company level over raw data. This result is significant at the $1 \%$ level. It suggests that the managers are constrained in their resources. In addition, investors focus on the analysis at the company level rather than at the more aggregate level (sector or country). This result also is significant at the $1 \%$ level. For most information categories, we observe that the need for information increases with the level of ESG integration. These observations lend strong support to the conclusion that ESG integration is much like traditional active management based on fundamental investing, in the sense that it is characterized by a strong need for company specific information.

ESG strategies can have a profoundly different focus on its individual dimensions. We therefore asked whether the investor has detailed instructions on how to deal with each of these individual ESG dimensions. The average response is reported in Table 4. This table reveals that $60 \%$ of the investors has detailed instructions on governance factors, whereas $43 \%$ of the investors has detailed instructions on environmental and social factors. The difference is statistically significant at a $1 \%$ level. By having a look at the individual data points, we observe that ESG investors have the same response to environmental and social factors. The higher score for governance factors is entirely due to a group of managers who have detailed instructions on governance factors but not on environmental and social factors.

In Table 5, we present the impact of ESG investing on portfolio construction. We first ask the respondents about their use of red flagging. Red flagging is the process of intensively monitoring and/or excluding stocks that are involved with serious environmental, social, or governance controversies or issues. Next, we ask whether ESG has an impact on the size of the investment universe. This is important, as a study by Hong and Kacperczyk (2009) has revealed that excluding a group of so-called sin stocks may have a serious negative impact on the performance of a portfolio. We also ask about the relevance of ESG investing for stock valuation and monitoring. As such, we want to check whether managers actually intend to use the information on a company level.

Table 5 reveals that $58 \%$ of the respondents uses red flagging. Hence, we conclude this is a widely applied technique. With less than $20 \%$ of the respondents using ESG investing to limit the investment universe, this is not the main strategy used in portfolio construction. This is an 
Table 3 Use of ESG information

\begin{tabular}{llllll}
\hline ESGSCORE & Raw data & Ratings & Analysis at company level & Analysis at sector level & Analysis at country level \\
\hline $2(n=12)$ & 0.23 & 0.38 & 0.77 & 0.31 & 0.31 \\
$3(n=60)$ & 0.33 & 0.43 & 0.88 & 0.38 & 0.17 \\
$4(n=44)$ & 0.34 & 0.59 & 0.89 & 0.50 & 0.50 \\
Total $(n=126)$ & 0.30 & 0.45 & 0.81 & 0.39 & 0.29 \\
\hline
\end{tabular}

Table 4 Manager focus

\begin{tabular}{lllll}
\hline ESG score & Environmental factors & Social factors & Governance factors & None of these \\
\hline $2(n=13)$ & 0.25 & 0.25 & 0.42 & 0.50 \\
$3(n=60)$ & 0.43 & 0.43 & 0.62 & 0.35 \\
$4(n=44)$ & 0.48 & 0.48 & 0.64 & 0.34 \\
Total $(n=126)$ & 0.43 & 0.43 & 0.60 & 0.36 \\
\hline
\end{tabular}

Table 5 Consequences of ESG information for portfolio construction and management

\begin{tabular}{lllllll}
\hline ESG score & Red flag & Limit universe & Stock valuation & Stock monitoring & Manage risk & None of these \\
\hline $1(n=9)$ & 0.33 & 0.00 & 0.00 & 0.00 & 0.00 & 0.11 \\
$2(n=13)$ & 0.53 & 0.00 & 0.46 & 0.31 & 0.54 & 0.00 \\
$3(n=60)$ & 0.74 & 0.20 & 0.65 & 0.55 & 0.43 & 0.61 \\
$4(n=44)$ & 0.63 & 0.27 & 0.41 & 0.44 & 0.67 & 0.05 \\
Total $(n=126)$ & 0.58 & 0.19 & 0.50 & & & 0.02 \\
\hline
\end{tabular}

interesting observation as many critics of ESG-in particular in the 1980s (Ennis and Parkhill (1986); Grossman and Sharpe (1986))_consider especially this as a widely used technique with a negative performance impact. Other popular use of ESG information is to manage the risks (67\%), stock valuation (50\%), and stock monitoring (44\%). Table 6 also provides an interesting insight with respect to the relation between the level of ESG integration and the reported consequences of ESG information and portfolio construction. Here, there appears to be an inverse U-shaped relationship between ESG score and the implications for portfolio construction and management. With the exception of the question relating to the limitation of the investment universe, the scores for almost all variables decrease from the second highest ESG score to the highest ESG score.

Table 6 Outperformance and ESG integration in 2011

\begin{tabular}{lll}
\hline ESG score & $\begin{array}{l}\text { Excess performance } \\
(1 \text { year })(\%)\end{array}$ & $\begin{array}{l}\text { Excess performance } \\
(3 \text { year })(\%)\end{array}$ \\
\hline $1(n=8)$ & 0.50 & 0.11 \\
$2(n=12)$ & 2.19 & 1.47 \\
$3(n=49)$ & -0.02 & 2.01 \\
$4(n=34)$ & -2.59 & 2.43 \\
Total $(n=103)$ & -0.57 & 1.94 \\
\hline
\end{tabular}

Whether ESG has an impact at all on financial performance is a question that has been addressed often before (see e.g., Derwall et al. 2005; Galema et al. 2008; Renneboog et al. 2008; Edmans 2011). Compared to most of this research, our sample is rather limited in size and scope. We only have information regarding the outperformance of the fund relative to their stated benchmark that reflects the individual characteristics of the manager. Therefore, this crude measure of outperformance also contains elements of systematic risk due to the absence of risk factors.

Table 6 suggests that the best crude one-year excess performance was observed among the lower ranking ESG managers, while the crude three-year excess performance was the best for the high ranking ESG managers. The table suggests that ESG investing pays off over a longer period of 3 years. Nevertheless, the results should be seen as only indicative on the relation between ESG investing and performance.

We also analyzed differences between portfolio managers originating from different domiciles. In doing so, we sorted all the data based on the domicile of the manager. Table 7 reports the results for those questions where domicile has a significant impact on the outcomes that we presented earlier.

From Panel A, we can observe that there is a remarkable difference in the perceptions of U.S. and European (including U.K.) domiciled portfolio managers. Portfolio 
Table 7 The impact of domicile on SRI

\begin{tabular}{|c|c|c|c|c|c|c|}
\hline \multirow[t]{2}{*}{ Location } & \multicolumn{4}{|c|}{ Impact of SRI on financial performance } & \multicolumn{2}{|l|}{ Relevant factors } \\
\hline & Negative $(\%)$ & Neutral $(\%)$ & Positive $(\%)$ & Long-term and risk reduction $(\%)$ & Env. and social factors $(\%)$ & Governance $(\%)$ \\
\hline \multicolumn{7}{|c|}{ Panel A: Perceived performance consequences and relevance of factors } \\
\hline U.K. & 2 & 24 & 53 & 20 & 29 & 39 \\
\hline U.S. & 3 & 40 & 17 & 40 & 31 & 71 \\
\hline Europe & 0 & 20 & 67 & 13 & 77 & 77 \\
\hline Other & 0 & 0 & 100 & 0 & 50 & 75 \\
\hline Location & Red flag & & nit universe $(\%)$ & Stock valuation $(\%)$ & Stock monitoring $(\%)$ & Manage risk $(\%)$ \\
\hline \multicolumn{7}{|c|}{ Panel B: Consequences for portfolio construction and management } \\
\hline U.K. & 86 & 14 & & 67 & 49 & 71 \\
\hline U.S. & 49 & 14 & & 34 & 26 & 63 \\
\hline Europe & 40 & 40 & & 50 & 70 & 83 \\
\hline Other & 50 & ( & & 75 & 50 & 50 \\
\hline
\end{tabular}

managers domiciled in the U.S. on average do not share the strong belief in the existence of a positive relation between SRI and performance by European and U.K. managers. However, more than with European and U.K. managers, they expected a positive impact on long-term performance and risk reduction. Another remarkable observation is that most U.S. and U.K. domiciled managers attach a low weight to environmental and social factors, while U.S. managers follow their European counterparts in attaching a high weight with respect to governance factors.

Domicile of the manager also affects the perceived consequences of SRI for portfolio construction and management. In Panel B of Table 7, we observe that U.K. managers rely more on red flagging as a tool to implement SRI, whereas European managers rely more on limiting the investment universe. The idea the SRI poses an alternative framing of fundamental analysis finds most support in the U.K., whereas European managers attach more value to stock monitoring. In all, our findings regarding the impact of domicile of asset managers suggest that SRI cannot be understood in isolation from contextual factors. This conclusion aligns with that of Gjølberg (2009) about CSR.

\section{Discussion and Conclusion}

When evaluating the outcomes of our survey, it appears difficult to find one single conclusion with respect to the impact of ESG investing on performance. Although our survey provides evidence regarding a positive performance over a 3-year period of time, the analysis is much too limited to generalize these results. As such, this is well in line with the findings elsewhere in the literature (e.g., CapelleBlancard and Monjon 2012; Humphrey and Tan 2014).
However, our survey also provides novel and interesting insights in the views and the actions of ESG managers.

The first insight is that a large majority of the managers is a signatory of the United Nations' PRI, indicating that the issue of SRI extends far beyond the domain of the group of managers who explicitly label or market themselves as socially responsible. We also observe that many managers indeed use ESG information in their investment processes.

In this respect, it is especially interesting to compare the results of our study with those of Chugh and Meador (1984) who also deployed a questionnaire among financial analysts. By the nature of their profession, analysts take an active stance on stock valuation. The survey of Chugh and Meador (1984) shows that analysts emphasize the long-run economic and financial performance of a company, in particular the long-term growth rate of earnings and longterm return on equity. They appear to attach a smaller weight to general economic conditions. At the same time, they believe that the quality of management is important, including their ability for strategic planning.

Somewhat surprisingly, our survey arrives at highly similar results: ESG investors tend to prefer analysis on individual companies over industry level analysis. With respect to the ESG dimensions, the strongest focus is on the governance of the firm, which has a close relationship with the quality of management. Although ESG investing is not the same as strategic planning, the successful realization of an ESG policy requires a lot of strategic planning because it directly relates to decisions with a long-term impact, including production technology, the use natural resources, and the social dimension, which refers to both the relation with the employees and the community. Improper management of the environmental and social dimension may 
have a serious and negative impact on the ability of the firm to conduct its business.

When we compare our findings with those of Berry and Junkus (2013) for retail investors, we find that the views between the two are highly aligned. Especially the fact that both professional and retail investors prefer to consider ESG in more holistic terms rather than using exclusions. However, it appears that for professional asset managers governance is more important than environmental and social factors. With retail investors, environmental and sustainability issues dominate as the major category associated with SRI (Berry and Junkus 2013).

While the processes surrounding ESG investing may already bear strong resemblance to fundamental investing in general, the beliefs of the managers with respect to the value of ESG information as a means to beat the benchmark provides even more compelling evidence. This is because we find that ESG investors have an overwhelming strong belief as to their ability to generating positive risk-adjusted returns, despite their disappointing track record of being able to do so. If ESG investors would have attached a large weight to their desire to change the world, we would have expected them to attach far less weight to their ability to beat the market. Apparently, ESG investors perceive their trade more like a sound business practice than as an activist approach on how to change the world.

We show that the asset manager's domicile has an important effect on the analysis. In particular, there are two important differences between U.S., U.K., and European domiciled investors in their perceptions of SRI: U.S. managers are much less optimistic about the benefits of SRI in terms of financial performance and they also belief that SRI has less impact on the investment process. Therefore, the idea that SRI is close to fundamental investing is more prevalent in Europe and the U.K.

Acknowledgments We want to thank the editor and an anonymous referee for their very helpful comments and suggestions. We are grateful to TKP Investments for providing assistance in acquiring the data. We want to thank the organizers and participants of the PRICDC Academic Network Conference in Paris, November 2013, for the discussion. The usual disclaimer applies.

Open Access This article is distributed under the terms of the Creative Commons Attribution License which permits any use, distribution, and reproduction in any medium, provided the original author(s) and the source are credited.

\section{Appendix 1: Questionnaire}

1. ESG factors relate to environmental (for example, carbon assessment, water and energy consumption, and waste management), social (for example, employee satisfaction, diversity, and human rights) and corporate governance factors (management, board independence, compensation). Do ESG factors play a role in your investment process? Choose the answer that best describes your approach.

a. No

b. Yes, it is implicitly incorporated in the financial numbers

c. Yes, it is in the back of my mind when analyzing a company

d. Yes, I make use of qualitative ESG information when analyzing a company

e. Yes, ESG information is explicitly processed in a quantitative way

f. Yes, I make use of both quantitative and qualitative ESG information

g. Yes, I use ESG information in another way (mention specific ESG policies and/or procedures)

2. As explained in the introductory text, this questionnaire is meant to measure if and how you integrate ESG factors into your investment process. In your opinion, how relevant are the following topics in identifying ESG integration?

\begin{tabular}{|c|c|c|c|c|}
\hline & $\begin{array}{l}1 \text { (not } \\
\text { relevant) }\end{array}$ & 23 & 4 & $\begin{array}{l}5 \text { (very } \\
\text { relevant) }\end{array}$ \\
\hline \multicolumn{5}{|l|}{$\begin{array}{l}\text { Being able to describe ESG } \\
\text { tactics/instructions }\end{array}$} \\
\hline \multicolumn{5}{|l|}{$\begin{array}{l}\text { Being able to list important ESG } \\
\text { factors }\end{array}$} \\
\hline \multicolumn{5}{|l|}{$\begin{array}{l}\text { Availability of ESG data/ } \\
\text { research }\end{array}$} \\
\hline \multicolumn{5}{|l|}{ Amount of money spent on ESG } \\
\hline \multicolumn{5}{|l|}{$\begin{array}{l}\text { Being able to provide concrete } \\
\text { examples }\end{array}$} \\
\hline $\begin{array}{l}\text { Presence of ESG expertise } \\
\text { (specialized staff/training) }\end{array}$ & & & & \\
\hline
\end{tabular}

3. During 2012, did you sell or reduce your position in a stock (partly) because of poor environmental, social, or governance concerns?

4. During 2012, did you buy or increase your position in a stock (partly) because of good environmental, social, or governance concerns?

5. In your opinion, what is the influence of ESG integration on the (risk-adjusted) outperformance of a mainstream mutual fund?
a. Negative
b. Neutral
c. Positive 

d. Risk reduction
e. Positive performance impact in long run

6. What type of ESG information do you use? (Multiple answers possible)
a. Raw data
b. Ratings
c. Analysis at company level
d. Analysis at sector level
e. Analysis at country level

7. Our firm has detailed instructions (concrete what-if rules) on how to deal with (multiple answers possible):
a. Environmental factors
b. Social factors
c. Governance factors
d. None of the above

8. 'Red Flagging' can be described as intensively monitoring and/or excluding stocks that are involved with serious environmental, social, or governance controversies/issues. Does your fund apply this strategy?

9. I use ESG information (multiple answers possible):
a. To specify/limit my investment universe
b. In the valuation of companies
c. To monitor a stock (check ESG related news)
d. To manage risks
e. None of the above

10. What was the outperformance (excess returns, excluding fees) of your fund over 2011?

11. What was 3-year annualized outperformance (excess returns, excluding fees) of your fund over the period 2009-2011?

\section{References}

Berry, T. C., \& Junkus, J. C. (2013). Socially responsible investing: An investor perspective. Journal of Business Ethics, 112, 707-720.
Capelle-Blancard, G., \& Monjon, S. (2012). Trends in the literature on socially responsible investment: Looking for the keys under the lamppost. Business Ethics: A European Review, 21, 239-250.

Chugh, L. C., \& Meador, J. W. (1984). The stock valuation process: The analyst's view. Financial Analysts Journal, 40(6), 41-48.

Derwall, J., Guenster, N., Bauer, R., \& Koedijk, K. (2005). The ecoefficiency premium puzzle. Financial Analysts Journal, 61(12), $51-63$.

Eccles, N. S., \& Viviers, S. (2011). The origins and meanings of names describing investment practices that integrate a consideration of ESG issues in the academic literature. Journal of Business Ethics, 104, 389-402.

Edmans, A. (2011). Does the stock market fully value intangibles? Employee satisfaction and equity prices. Journal of Financial Economics, 101, 421-640.

Ennis, R. M., \& Parkhill, R. L. (1986). South African divestment: Social responsibility or fiduciary folly? Financial Analysts Journal, 42(4), 30-38.

Eurosif. (2014). European SRI study. Brussels: Eurosif.

Galema, R., Plantinga, A., \& Scholtens, B. (2008). The stocks at stake: Return and risk in socially responsible investment. Journal of Banking \& Finance, 32, 2646-2654.

Gjølberg, M. (2009). The origin of corporate social responsibility: Global forces or national legacies? Socio-Economic Review, 7, 605-637.

Graham, B., \& Dodd, D. L. (1934). Security analysis: Principles and technique. Columbus, OH: McGraw-Hill.

Grossman, B. R., \& Sharpe, W. F. (1986). Financial implications of South African divestment. Financial Analysts Journal, 42(4), $15-29$.

Hong, H., \& Kacperczyk, M. (2009). The price of sin: the effect of social norms on markets. Journal of Financial Economics, 93, $15-36$.

Humphrey, J. E., \& Tan, D. T. (2014). Does it really hurt to be responsible? Journal of Business Ethics, 122, 375-386.

Johnsen, B. D. (2003). Socially responsible investing: A critical appraisal. Journal of Business Ethics, 43, 219-222.

Kempf, A., \& Osthoff, P. (2008). SRI Funds, Nomen est Omen. Journal of Business, Finance \& Accounting, 35, 1276-1294.

Renneboog, L., ter Horst, J., \& Zhang, C. (2008). Socially responsible investments: Institutional aspects, performance and investment behavior. Journal of Banking \& Finance, 32, 1723-1742.

Shiller, R. J. (2013). Capitalism and financial innovation. Financial Analysts Journal, 69(1), 21-25. 